50. Johnson, D. A., Asay, K. H., Tieszen, L. L., Ehleringer, J. R. and Jefferson, P. G., Carbon isotope discrimination: potential in screening cool-season grasses for water-limited environments. Crop Sci., 1990, 30, 338-343.

51. Wang, Y., Zhang, W., Song, L., Zou, J., Su, Z. and Wu, W., Transcriptome analyses show changes in gene expression to accompany pollen germination and tube growth in Arabidopsis. Plant Physiol., 2008, 148(3), 1201-1211.

52. Zamir, D., Pollen gene expression and selection: applications in plant breeding. In Isozymes in Plant Genetics and Breeding (eds Tanksley, S. D. and Orton, T. J.), Elsevier, New York, 1983, pp. 313-330.

53. Fukai, S. and Cooper, M., Development of drought-resistant cultivars using physio-morphological traits in rice. Field Crops Res., 1994, 40, 67-86.

54. Jongdee, B., Fuka, S. and Cooper, M., Leaf water potential and osmotic adjustment as physiological traits to improve drought tolerance in rice. Field Crops Res., 2002, 76(2-3), 153-163.

55. Nayyar, H., Accumulation of osmolytes and osmotic adjustment in water stressed wheat (Triticum aestivum) and maize (Zea mays) as affected by calcium and its antagonists. Environ. Exp. Bot., 2003, 50(3), 253-264.

56. Lacerda, C. F., Cambraia, J., Oliva, M. A. and Ruiz, H. A., Osmotic adjustment in roots and leaves of two sorghum genotypes under NaCl stress. Braz. J. Plant Physiol., 2003, 15(2), 113-118.

57. Chimenti, C. A., Marcantonio, M. and Hall, A. J., Divergent selection for osmotic adjustment results in improved drought tolerance in maize (Zea mays L.) in both early growth and flowering phases. Field Crops Res., 2006, 95(3), 305-315.

58. Pedersen, S., Simonsen, V. and Loeschcke, V., Overlap of gametophytic and sporophytic gene expression in barley. Theor. Appl. Genet., 1987, 75(1), 200-206.

59. Hormaza, J. I. and Herrero, M., Dynamics of pollen tube growth under different competition regimes. Sex. Plant Reprod., 1996, 9, $153-160$.

60. Liu, C., Liu, Y., Guo, K., Dayong, F. D., Li, G., Zheng, Y., Yu, L. and Yang, R., Effect of drought on pigments, osmotic adjustment and antioxidant enzymes in six woody plant species in karst habitats of south western China. Environ. Exp. Bot., 2011, 71, 174183

61. Sayfzadeh, S. and Rashidi, M., Response of antioxidant enzymes activities of sugar beet to drought stress. J. Agric. Biol. Sci., 2011, 6, 27-33.

62. Ji, X., Shiran, B., Wan, J., Lewis, D. C., Jenkins, C. L. and Condon, A. G., Importance of pre-anthesis anther sink strength for maintenance of grain number during reproductive stage water stress in wheat. Plant Cell Environ., 2010, 33, 926-942.

Received 3 August 2017; revised accepted 11 September 2018

doi: $10.18520 / \mathrm{cs} / \mathrm{v} 116 / \mathrm{i} 2 / 279-285$

\section{Synthesis and characterization of nano-selenium and its antibacterial response on some important human pathogens}

\section{Angamuthu Ananth, Venkidusamy Keerthika and Muthuswami Ruby Rajan*}

Department of Biology, The Gandhigram Rural Institute (Deemed to be University), Gandhigram 624 302, India

Synthesis of nano-selenium was achieved from sodium selenite by a simple precipitation method using the reducing power of ascorbic acid. The high-speed centrifuge was used to separate selenium nanoparticles from aqueous solution. The selenium nanoparticles were characterized by $U V-V$ is spectroscopy, $\mathrm{X}$-ray diffraction, Fourier transform-infrared spectroscopy (FT-IR), scanning electron microscopy, energy dispersive $X$-ray analysis and transmission electron microscope. Presence of various functional groups responsible for the production and stability of the nanoparticles was confirmed by FT-IR. Some of the important human pathogens like Staphylococcus aureus, Escherichia coli and Pseudomonas aeruginosa were used for examining the antibacterial response of selinium nanoparticles. Results of this study demonstrate that synthesized selenium nanoparticles exhibit a spherical shape with average diameter range between 15 and $18 \mathrm{~nm}$. They can be used as an antibacterial agent and also in medicinal applications for the treatment of humans with certain bacterial diseases.

Keywords: Antibacterial activity, characterization, human pathogens, synthesis, selenium nanoparticles.

NANOTECHNOLOGY is able to observe, measure, manipulate and manufacture things at the nanometre scale ${ }^{1}$. Currently, many nanosubstances are produced with the help of this emanating technology which occupies an important place in scientific research. Chemical composition, size, shape and morphology of nanoparticles are dealt within the synthesis process which is considered as a vital step in nanotechnological research ${ }^{2}$. Due to the size of the nanoparticles, their properties accustomed to giving a larger surface area compared to the bulk material. Thus, materials made up in such a way will have atoms that have more contact with the external environment; whereas those which are considered as bulk hold the atoms closer to the centre ${ }^{3}$. Application of nanoparticles can be associated with many fields like medical, food industries, environmental studies, electronics production, energy generation and agriculture ${ }^{4}$.

The most commonly used nanoparticles which have wide applications are silver, gold, zinc, copper and iron.

*For correspondence. (e-mail: mrrrajanbio@gmail.com) 
For this study, an essential mineral selenium (Se) was used. This is a metalloid and an essential micronutrient. It plays vital functions in the human body by improving the action of enzymes such as glutathione peroxidase and seleno-enzymes which defend the body against immunityrelated diseases ${ }^{5}$. As a semiconductor selenium possesses optical, photoconductor and catalytic properties. It also has some uncommon properties like efficient chemical and biological functions compared to bulk materials ${ }^{6}$.

There arises complexity with the frequent use of antibiotics in the medical field; among them bacterial resistance is a major problem faced by the microbiologists. So there is a crucial need to develop a substitute operator to control pathogenic bacterial growth. It has been reported that metalloid nanoparticles can be used as disinfectants which are applied in the food industries to preserve food materials ${ }^{7}$. Though necessary, very less support has been extended to the pharmaceutical industry to design new antibacterial operators. To overcome the resistance of microorganisms to antibiotics, it is indispensable to design a non-antibiotic treatment ${ }^{8}$.

Silver nanoparticles are generally used for their antimicrobial function. Hence their functions are unsettled and the latest choice is Se nanoparticles which have many medical applications. Due to their unique morphological and chemical nature, Se nanoparticles are more reactive and lethal to bacteria ${ }^{9}$. Se nanoparticles have also been utilized in food preservation methods like packing of foods items and antiseptic coating over food materials ${ }^{8}$. Studies have been carried out to highlight the disinfectant properties of Se nanoparticles against Trichophyton rubrum $^{10}$, Candida albicans ${ }^{11}$, Pseudomonas aeruginosa and Proteus mirabilis ${ }^{12}$. The present study focuses on a solution to the problem of drug resistance.

Sodium selenite was used for producing Se nanoparticles $\left(\mathrm{Na}_{2} \mathrm{SeO}_{3}\right)$ where ascorbic acid $\left(\mathrm{C}_{6} \mathrm{H}_{8} \mathrm{O}_{6}\right)$ acted as a reducing operator ${ }^{13}$. A stock of aqueous solution of $100 \mathrm{mM} \mathrm{Na} \mathrm{SeO}_{3}$ and $50 \mathrm{mM} \mathrm{C}_{6} \mathrm{H}_{8} \mathrm{O}_{6}$ was prepared in $1: 4$ ratio. The solution was kept under magnetic stirring condition at different rpm (rotation per minute) and at ambient temperature for $30 \mathrm{~min}$. The mixtures were allowed to react with each other in the concentrated form until a change was observed from colourless to red colour. Then the solution was centrifuged at $3000 \mathrm{rpm}$, pellets were collected and nano-selenium was obtained.

Chemically synthesized nano-selenium was determined by UV-Vis spectroscopy using an automated spectrometer (Spectro UV-Vis double beam DUV 3500). The morphology and elements percentage of nano-selenium were measured using transmission electron microscopy (TEM) and scanning electron microscopy (SEM; LEO 1455 VP) provided with energy dispersive X-ray (EDX) analytical instrument. Fourier transform infrared spectroscopy (FT-IR; JASCO (FTIR-6200)) was employed to explore the functional groups present in the sample. X-ray diffraction (XRD) analysis was done using an X-ray dif- fractometer (Shimadzu XRD-6000, Japan) to analyse the crystalline nature of the sample.

After characterization, the antibacterial activity of nano-selenium against $S$. aureus which is Gram-positive, and $E$. coli and P. aeruginosa which are Gram-negative strains was assessed by well diffusion technique. An active bacterial culture was obtained by shifting the culture to nutrient broth containing test tubes from stock, and it was incubated for $24 \mathrm{~h}$ at $37^{\circ} \mathrm{C}$ to obtain fresh and active bacterial culture. For the assay, approximately $25 \mathrm{ml}$ of nutrient agar plates was prepared, and $100 \mu \mathrm{l}$ of bacterial culture was swabbed evenly over this with the aid of disinfected cotton bud. Then $50 \mu \mathrm{l}$ of Se nanoparticles $(1 \mathrm{mg}$ of Se nanoparticles diluted in $1 \mathrm{ml}$ of distilled water) was poured in one well, while an ampicillin antibiotic disc $(50 \mu \mathrm{g})$ and distilled water in another well served as control. Zone of inhibition on these plates was observed after incubation at $37^{\circ} \mathrm{C}$ for about a day.

Se nanoparticles of various shapes and sizes were synthesized by chemical precipitation method. Chemical reduction method helps in maintaining better uniformity of the particles which can be used for various applications, especially in medicine. Nguyen et ll. $^{8}$ fabricated nanoselenium from $\mathrm{Na}_{2} \mathrm{SeO}_{3}$ using glutathione and bovine serum albumin as reducing agents, with an average diameter of $79 \mathrm{~nm}$. Similarly, Li et $a{ }^{14}{ }^{14}$ synthesized Se nanoparticles using L-cysteine as a reducing agent. The change from colourless to red colour indicates the formation of nano-selenium

$$
\begin{aligned}
& \mathrm{Na}_{2} \mathrm{SeO}_{3} \rightarrow 2 \mathrm{Na}^{+}+\mathrm{SeO}_{3}^{2-}, \\
& \mathrm{C}_{6} \mathrm{H}_{8} \mathrm{O}_{6} \rightarrow \mathrm{C}_{6} \mathrm{H}_{7} \mathrm{O}_{6}^{-}+\mathrm{H}^{+}, \\
& 2 \mathrm{Na}^{+}+\mathrm{SeO}_{3}^{2-}+\mathrm{C}_{6} \mathrm{H}_{7} \mathrm{O}_{6}^{-}+\mathrm{H}^{+}+\mathrm{H}_{2} \mathrm{O} \\
& \rightarrow \mathrm{Se}+2 \mathrm{Na}^{+}+\mathrm{C}_{6} \mathrm{H}_{7} \mathrm{O}_{6}^{-}+\mathrm{H}_{2} \mathrm{O} .
\end{aligned}
$$

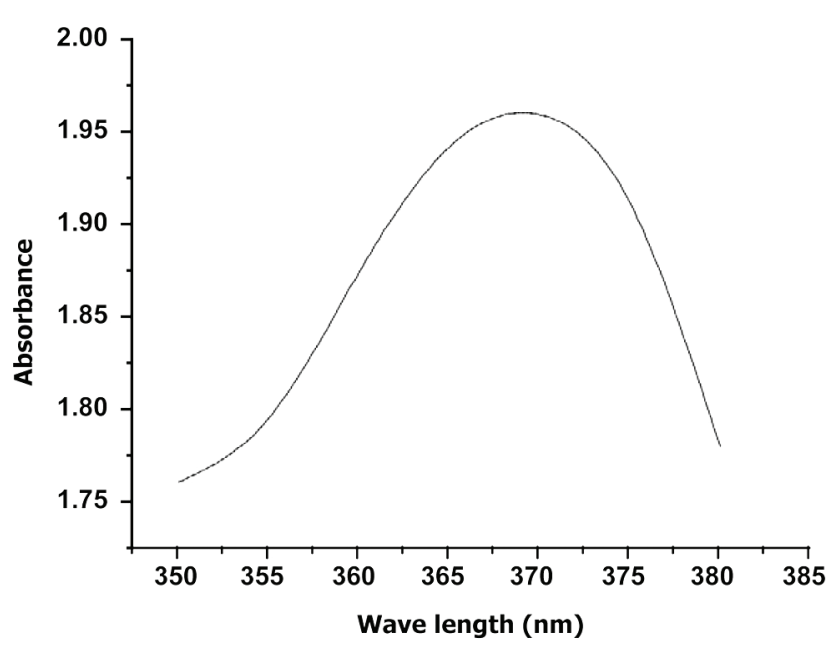

Figure 1. UV-Vis analysis of nano-selenium. 


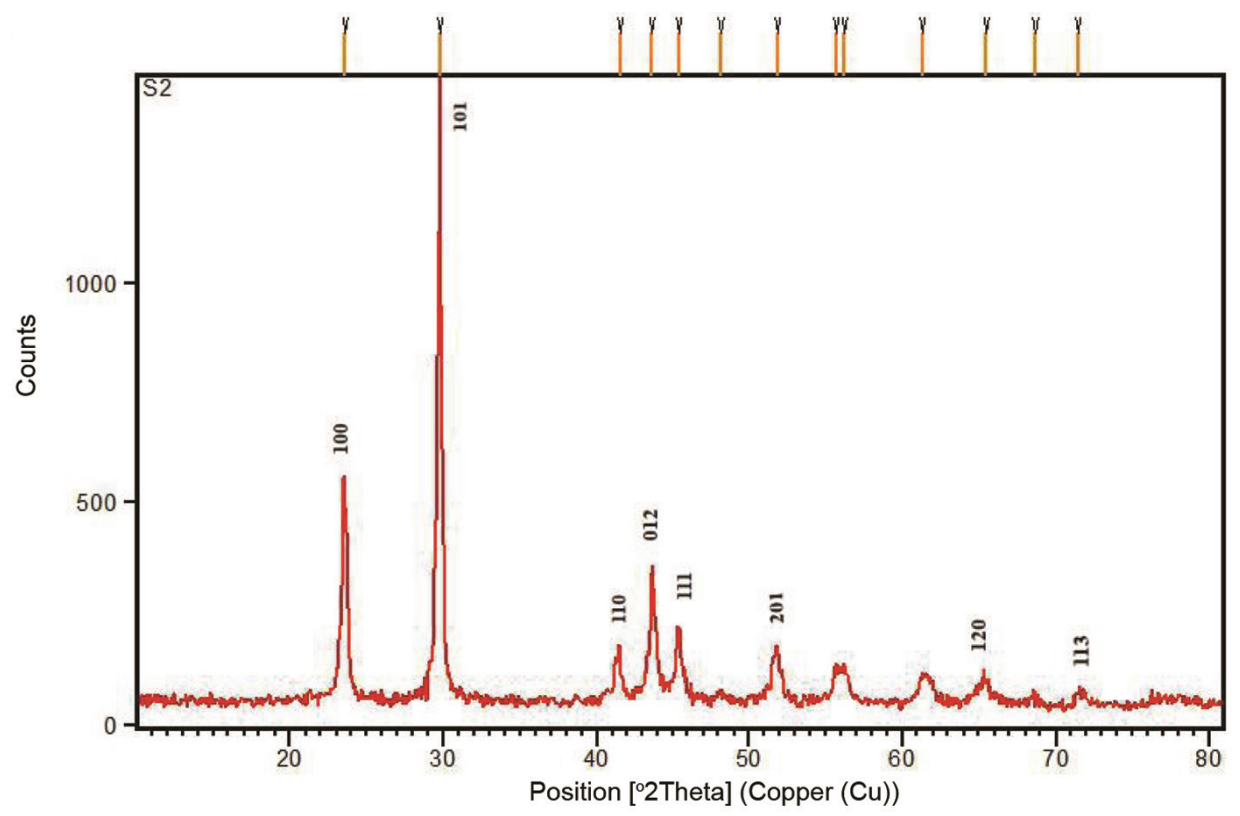

Figure 2. X-ray diffractometer analysis of nano-selenium.

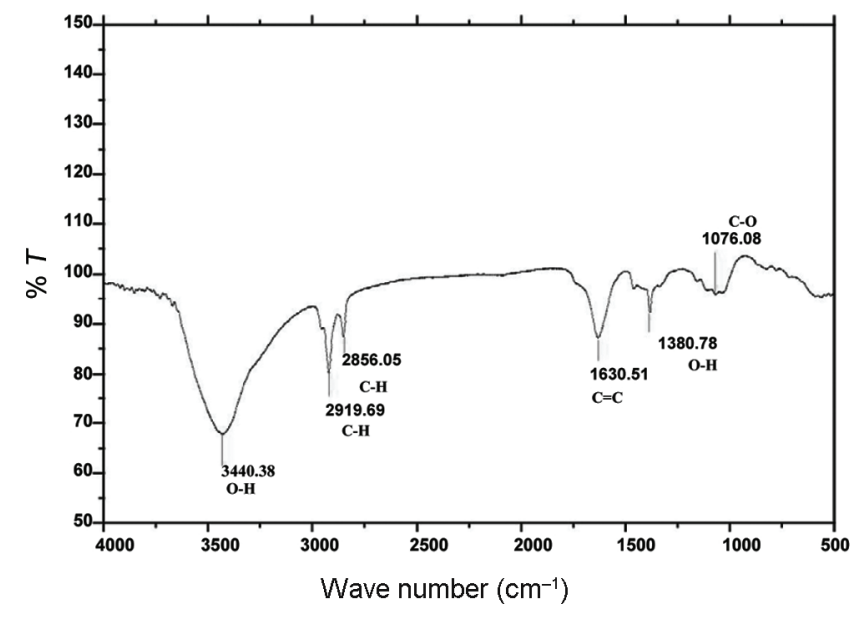

Figure 3. Fourier-transform infrared spectroscopy analysis of nanoselenium.

Conversion of selenium ions into nano-selenium during reaction with ascorbic acid was observed as a result of the colour change. The most easily observed property of nanoparticles is their change in colour at different sizes. So as the size changes, the colour of the particles formed will also change; absorbing in the visible region of the spectrum. Thus, UV-Vis spectrum is the most basic and important technique for the identification and characterization of nanoparticles ${ }^{15}$. In UV analysis, chemically synthesized Se nanoparticles were scanned under a spectrophotometer between 350 and $400 \mathrm{~nm}$; the highest peak was visible at $370 \mathrm{~nm}$ (Figure 1). Malhotra et al. ${ }^{13}$ observed similar strong absorbance peak between 320 and $550 \mathrm{~nm}$, with a maximum at $390 \mathrm{~nm}$. Nano-selenium obtained using Klebsiella pneumonia also showed an ab- sorption band between 200 and $300 \mathrm{~nm}$ (ref. 16). Zhang et al. $^{17}$ and Harikrishnan et al. ${ }^{18}$ have fabricated nanoselenium using Pseudomonas alcaliphila and S. cerevisiae, which showed absorption peaks at 200 and $300 \mathrm{~nm}$ respectively.

The crystallite nature of chemically prepared nanoselenium was examined by XRD. This analytical method aids in the determination of crystallite materials and also provides details of unit cell dimensions. Dorofeey et al. ${ }^{19}$ reported that shape and breadth of reflection help detect substructures in the nanosubstances. The obtained nanoselenium was highly crystalline and all diffraction peaks have been well indexed as $23.5616^{\circ}, 29.7572^{\circ}, 41.4821^{\circ}$, $43.6615^{\circ}, 45.4223^{\circ}, 48.1882^{\circ}, 51.8509^{\circ}, 55.6733^{\circ}$, $56.2526^{\circ}, 61.3117^{\circ}, 65.4128^{\circ}, 68.6359^{\circ}$ and $71.4573^{\circ}$, which correspond to $100,101,110,012,111,200,201$, $003,112,013,120,211$ and 113 crystal planes respectively, in accordance with JCPDS 86-2246 (Figure 2). Using Scherrer's equation the crystalline nature of nanoselenium was confirmed.

$$
D=0.94 \lambda / \beta \cos \theta \text {. }
$$

The crystallite size of nano-selenium was found to be $28 \mathrm{~nm}$. A similar study was also carried out by Ghada and Bahig $^{20}$, who identified sharp peaks numbers from 5 to 80 in the $2 \theta$ values.

FT-IR spectra were captured in the frequency range from 400 to $4000 \mathrm{~cm}^{-1}$. This frequency absorption helps identify elements involved in the fabrication of nanoselenium. Figure 3 shows the FT-IR spectra of chemically synthesized nano-selenium. The spectrum of nanoselenium has vibrational and stretching functions at wave 

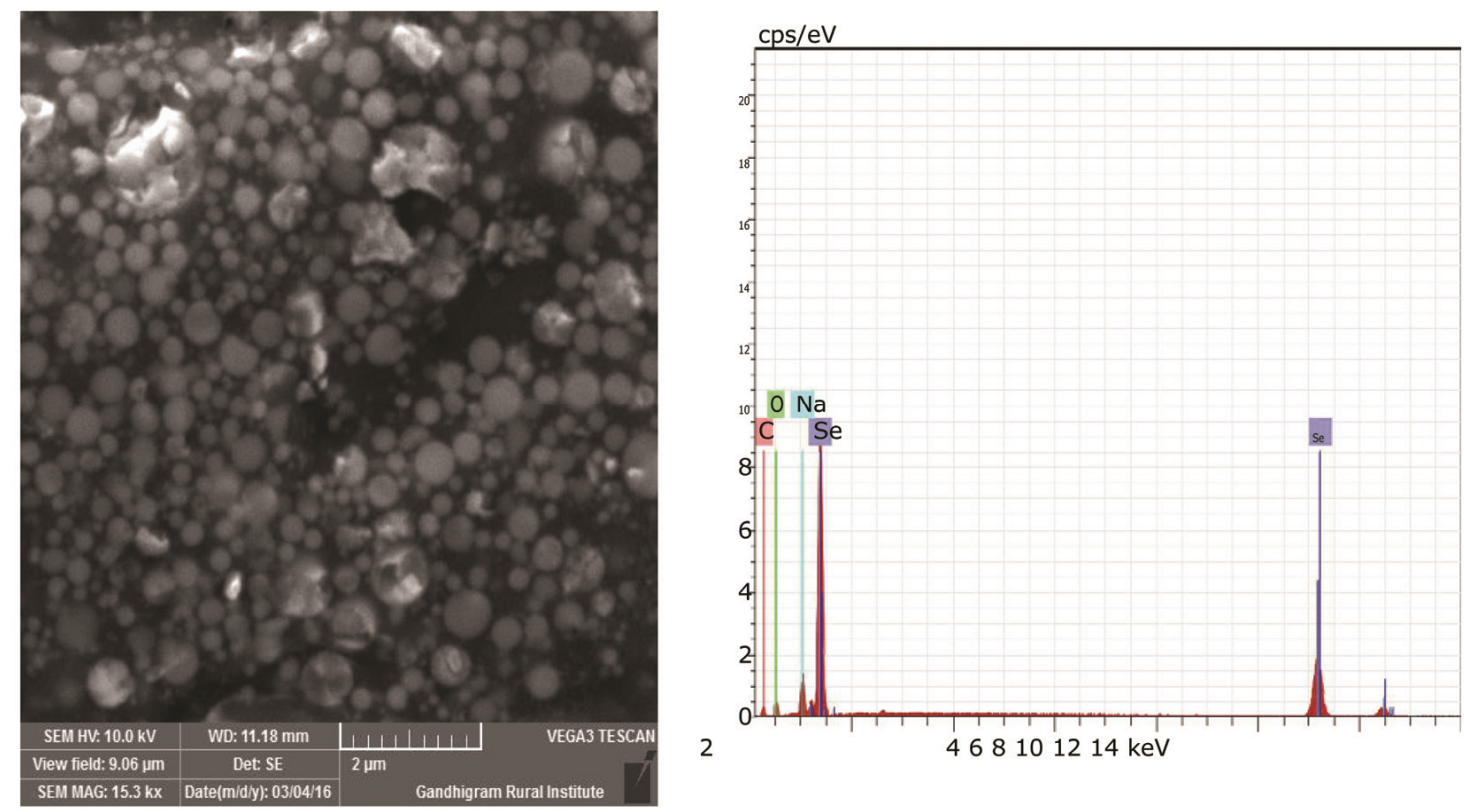

Figure 4. Scanning electron microscopy-energy dispersive image of nano-selenium.

Table 1. Fourier transform-infrared spectroscopy analysis of nanoselenium

\begin{tabular}{llll}
\hline $\begin{array}{l}\text { Frequency } \\
\left(\mathrm{cm}^{-1}\right)\end{array}$ & $\begin{array}{c}\text { Functional } \\
\text { group }\end{array}$ & $\begin{array}{c}\text { Types of } \\
\text { vibration }\end{array}$ & Intensity \\
\hline 3440.38 & O-H & Stretch bonded & Strong, broad \\
2919.69 & C-H & Stretch bonded & Strong \\
2856.05 & C-H & Stretch bonded & Strong \\
1630.51 & C=C & Stretch bonded & Variable \\
1380.78 & O-H & Bending bonded & Medium \\
1076.08 & C-O & Stretch bonded & Strong \\
\hline
\end{tabular}

numbers $2919.69,1630.51,1380.78$ and $1076.08 \mathrm{~cm}^{-1}$ corresponding to $\mathrm{C}-\mathrm{H}, \mathrm{C}=\mathrm{C}, \mathrm{O}-\mathrm{H}$ and $\mathrm{C}-\mathrm{O}$ respectively, suggesting the presence of reducing groups aiding in nano-selenium fabrication (Table 1). The band at $2361 \mathrm{~cm}^{-1}$ is the $\mathrm{C}-\mathrm{H}$ stretch of aryl acid. The strong band found at $1654 \mathrm{~cm}^{-1}$ is characteristic of $\mathrm{C}=\mathrm{C}$ stretch of an aromatic ring, $\mathrm{N}-\mathrm{H}$ bending of amine and a $\mathrm{C}=\mathrm{O}$ stretch of polyphenols. The $\mathrm{C}-\mathrm{O}$ group can be indicated by peaks observed between 1100 and 1000 (ref. 21). Mallikarjuna et $a l^{22}$ reported that bands at $3250 \mathrm{~cm}^{-1}$ indicate $\mathrm{O}-\mathrm{H}$ groups in water and alcohol.

SEM is used for studying morphological characteristics of nanoparticles. It is capable of imaging photographs with high resolution. EDX diffraction is commonly associated with SEM, which is used to analyse the chemicallevel elemental composition of samples ${ }^{23}$. SEM image of chemically synthesized Se nanoparticles revealed that it is spherical in shape and uniformly distributed (Figure $4 a$ ). Hariharan et $a .^{24}$ used this technique for analysing the morphology and structure of Se nanoparticles, and produced spherical and smaller-sized particles ranging between 30 and $100 \mathrm{~nm}$. EDX analysis proves that the obtained nanoparticles are pure in nature (Figure $4 b$ ). The chemical constituents of the sample were analysed by Razi et al. ${ }^{25}$, which yielded about $99 \%$ pure selenium. Keerthika et $a l .{ }^{26}$ have synthesized iron oxide nanoparticles that are almost globular in shape and range in size between 30 and $110 \mathrm{~nm}$.

Size and morphology of nano-selenium were identified by this technique. Nano-selenium exhibits spherical shape with an average diameter between 15 and $18 \mathrm{~nm}$. Figure $5 a$ and $b$ shows TEM image and its histogram of chemically synthesized nano-selenium respectively. These images depict that the shape of nano-selenium is spherical, which is in conflict with the SEM analysis result. Hu et $a{ }^{27}$ have also reported a comparable result (nanoselenium of size $20-80 \mathrm{~nm}$ ). Chen et al. ${ }^{28}$ synthesized spherically shaped and 44-92 nm sized nano-selenium.

Figure 6 shows the antibacterial response of nanoselenium against $S$. aureus, E. coli and P. aeruginosa. Hamouda et ll $^{29}$ found that nanoparticles can play a vital role in designing efficient bactericidal substances. Klabunde et $a l .{ }^{30}$ and Stoimenov et al. ${ }^{31}$ reported that metal nanoparticles display excellent antibacterial activity against disease-causing bacteria. The zone of inhibition of nano-selenium against the three above-mentioned strains was measured (Table 2), which revealed that nano-selenium possesses antibacterial efficiency. The antibacterial effect may be due to the fact that at this particular concentration nano-selenium interact with the bacterial cell surface and penetrates into the cell, thus causing damage. As concentration of the nanoparticles 

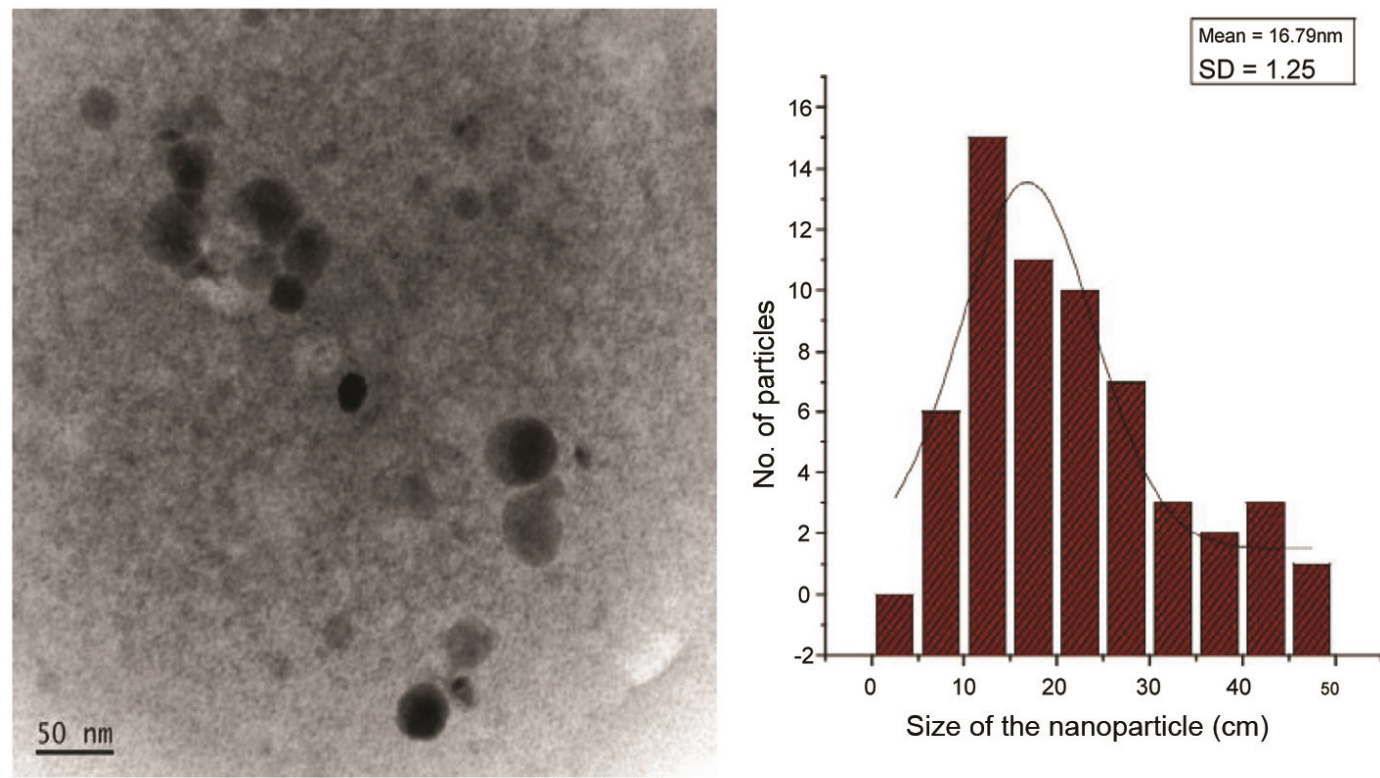

Figure 5. Transmission electron microscopy analysis of nano-selenium.
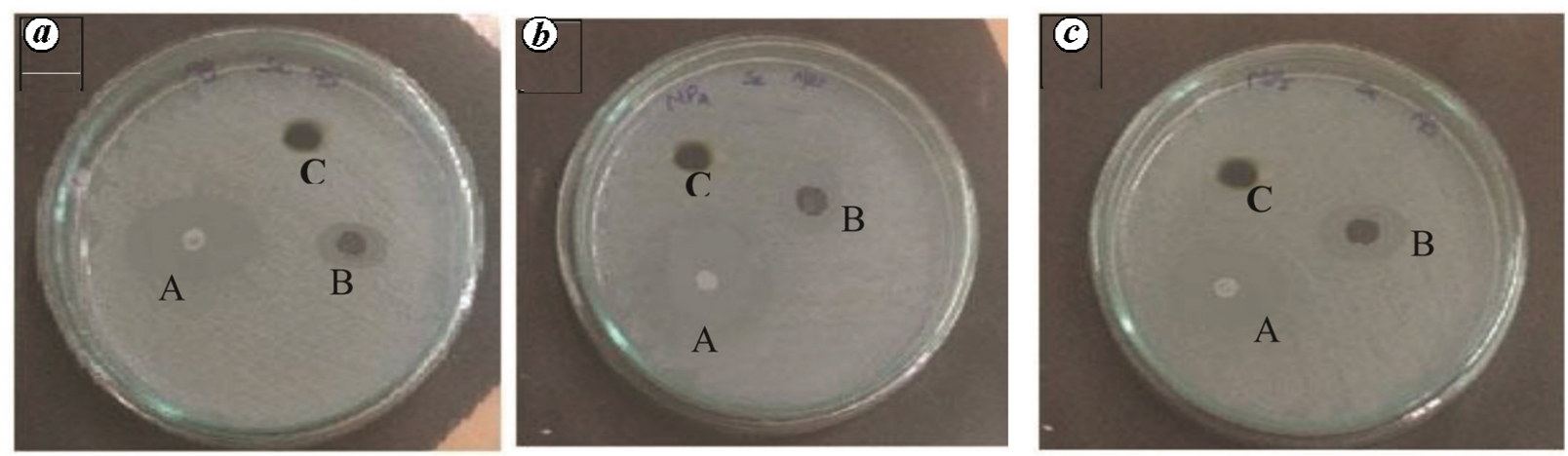

Figure 6. Antibacterial response of nano-selenium. a, Pseudomonas aeruginosa; b, Staphylococcus aureus; c, Escherichia coli. A, Antibiotic (ampicillin); B, Selenium nanoparticles; C, Control.

Table 2. Zone of inhibition of nano-selenium against pathogens

\begin{tabular}{lcc}
\hline & \multicolumn{2}{c}{ Zone of inhibition (mm) } \\
\cline { 2 - 3 } Pathogens & Nano-selenium & Antibiotic (ampicillin) \\
\hline Pseudomonas aeruginosa & 18 & 20 \\
Staphylococcus aureus & 21 & 22 \\
Escherichia coli & 18 & 21 \\
\hline
\end{tabular}

increases, their bactericidal response also increases ${ }^{32}$. Chudobova et al. $^{33}$ found that $S$. aureus is inhibited by nano-selenium at 60 times better than the control. More research needs to be carried out to deduce the antimicrobial response of the disease causing microorganisms. This study is focused on fabrication of highly stable nano-selenium (15-18 nm size) using precipitation method with simple ingredients which can be used as an effective antibacterial agent similar to that of ampicillin.
This antibiotic is used to prevent and treat a number of bacterial diseases or infections in humans, like respiratory tract infections, urinary tract infections, meningitis, whooping cough, salmonellosis and endocarditis. Hence, nano-selenium can be an alternative to antibiotics like ampicillin.

Thus, in this study Se nanoparticles were synthesized through chemical precipitation method using ascorbic acid as the reducing agent. The fabricated nano-selenium was characterized using UV-Vis, XRD, FT-IR, TEM and SEMEDX. It exhibits a spherical shape with an average diameter between 15 and $18 \mathrm{~nm}$, which was confirmed by TEM analysis. Chemically synthesized Se nanoparticles could be a potential antibacterial agent to treat humans affected with bacterial diseases caused by important pathogenic bacteria.

1. Mongillo, F. J., Nanotechnology, Greenwood Press, Westport, Connecticut, USA, 2007, p. 101. 
2. Maynard, A. D., Baron, P. A., Foley, M., Shvedova, A. A., Kisin, E. R. and Castranova, V., Exposure to carbon nanotube material: aerosol release during the handling of unrefined single-walled carbon nanotube material. J. Toxicol. Environ. Health, Part A, 2004, 67, 87-108.

3. Mohanraj, V. J. and Chen, Y., Nanoparticles - a review. Trop. J. Pharm. Res., 2006, 5(1), 561-573.

4. Wang, Y. and Herron, N., Nanometer-sized semiconductor clusters: materials synthesis, quantum size effects, and photophysical properties. J. Phys. Chem., 1991, 95, 525-532.

5. Romero-Perez, A., Garcia-Garcia, E. and Zavaleta-Manceraetal, A., Designing and evaluation of sodium selenite nanoparticles in vitro to improve selenium absorption in ruminants. Vet. Res. Commun., 2010, 34, 71-79.

6. Nath, S., Ghosh, S. K., Panigahi, S., Thundat, T. and Pal, T., Synthesis of selenium nanoparticle and its photocatalytic application for decolorization of methylene blue under UV irradiation. Langmuir, 2004, 20, 7880.

7. Cremonini, E. et al., Biogenic selenium nanoparticles: characterization, antimicrobial activity and effects on human dendritic cells and fibroblasts. Microb. Biotechnol., 2016, 9(6), 758-771.

8. Nguyen, T. H. D., Vardhanabhuti, B., Lin, M. and Mustapha, A., Antibacterial properties of selenium nanoparticles and their toxicity to Caco-2 cells. Food Control, 2017, 77, 17-24.

9. Choi, O., Deng, K. K., Kim, N. J., Ross Jr, L., Surampalli, R. Y. and $\mathrm{Hu}, \mathrm{Z}$., The inhibitory effects of silver nanoparticles, silver ions, and silver chloride colloids on microbial growth. Water Res., 2008, 42(12), 3066-3074.

10. Yip, J., Liu, L., Wong, K. H., Leung, P. H., Yuen, C. W. M. and Cheung, M. C., Investigation of antifungal and antibacterial effects of fabric padded with highly stable selenium nanoparticles. J. Appl. Polym. Sci., 2014, 131(17), 40728 (1-8).

11. Kheradmand, E., Rafii, F., Yazdi, M. H., Sepahi, A. A., Shahverdi, A. R. and Oveisi, M. R., The antimicrobial effects of selenium nanoparticle-enriched probiotics and their fermented broth against Candida albicans. DARU, 2014, 22(1), 48.

12. Shakibaie, M., Forootanfar, H., Golkari, Y., MohammadiKhorsand, T. and Shakibaie, M. R., Anti-biofilm activity of biogenic selenium nanoparticles and selenium dioxide against clinical isolates of Staphylococcus aureus, Pseudomonas aeruginosa and Proteus mirabilis. J. Trace Elem. Med. Biol., 2015, 29, 235-241.

13. Malhotra, S., Jha, N. and Desai, K., A superficial synthesis of selenium nanospheres using wet chemical approach. Int. J. Nanotechnol. Appl., 2014, 3(4), 7-14.

14. Li, Q., Chen, T. and Yang, F., Facile and controllable one-step fabrication of selenium nanoparticles assisted by L-cysteine. Mater. Lett., 2010, 64, 614-617.

15. Khurana, J. M. and Vij, K., Nickel nanoparticles as semiheterogeneous catalyst for one-pot, three-component synthesis of 2-amino4H-pyrans and pyran annulated heterocyclic moieties. Synth. Commun., 2013, 43(17), 2294-2304.

16. Fesharaki, P. J., Nazari, P., Shakibaie, M., Rezaie, S., Banoee, M., Abdollahi, M. and Shahverdi, A. R., Biosynthesis of selenium nanoparticles using Klebsiella Pneumoniae and their recovery by a simple sterilization process. Braz. J. Microbiol., 2010, 41, 461466.

17. Zhang, W., Chen, Z., Liu, H., Zhang, L., Gao, P. and Li, D., Biosynthesis and structural characteristics of selenium nanoparticles by Pseudomonas alcaliphila. Colloids Surf., B, 2011, 88, 196-201.

18. Harikrishnan, H., Abdullah, N. A., Ponmurugan, K. and Shyam Kumar, R., Microbial synthesis of selenium nanocomposite using Saccharomyces Cerevisiae and its antimicrobial activity against pathogens causing nosocomial infection. Chalcogenide Lett., 2012, 9, 509-515.

19. Dorofeey, G. A., Streletskii, A. N., Povstugar, I. V., Protasov, A. V. and Elsukov, E. P., Determination of nanoparticle sizes by X-ray diffraction. Colloid J., 2012, 74, 675-685.
20. Khiralla, G. M. and El-Deeb, B. A., Antimicrobial and antibiofilm effects of selenium nanoparticles on some food borne pathogens. LWT-Food Sci. Technol., 2015, 63, 1001-1007.

21. Prasad, K. S., Patel, H., Patel, T., Patel, K. and Selvaraj, K., Biosynthesis of Se nanoparticles and its effect on UV-induced DNA damage. Colloids Surf. B, 2013, 103, 261-266.

22. Mallikarjuna, K., Narasimha, G., Dillip, G. R., Praveen, B. and Shreedhar, B., Green synthesis of silver nanoparticles using Ocimum leaf extract and their characterization. Dig. J. Nanomater. Biostruct., 2011, 6, 181-186.

23. Pal, D., Mishra, P., Sachan, N. and Ghosh, A. K., Biological activities and medicinal properties of Cajanus cajan (L) Millsp. J. Adv. Pharm. Technol. Res., 2011, 2(4), 207-214.

24. Hariharan, Al-Dhabi, N. A., Karuppiah, P. and Rajaram, S. K., Microbial synthesis of selenium nanocomposite using Saccharomyces cerevisiae and its antimicrobial activity against pathogens causing nosocomial infection. Chalcogenide Lett., 2012, 12, 509515.

25. Razi, K., Sarraf Maamoury, M. R. and Banihashemi, S., Preparation of nano selenium particles by water solution phase method from industrial dust. Int. J. Nano Dimens., 2011, 1, 261-267.

26. Keerthika, V., Ramesh, R. and Rajan, M. R., Toxicity assessment of iron oxide nanoparticles in Labeo rohita. Int. National J. Fish. Aquat. Stud., 2017, 5(4), 1-6.

27. Hu, C. H., Li, Y. I., Xiong, L., Zhnag, H. M., Song, J. and Xia, M. S., Comparative effects of nano elemental selenium and sodium selenite on selenium retention in broiler chickens. Anim. Feed Sci. Technol., 2012, 177, 204-210.

28. Chen, T., Wonga, Y.-S., Zhengb, W., Baib, Y. and Huangb, L., Selenium nanoparticles fabricated in Undaria pinnatifida polysaccharide solutions include mitochondria-mediated apotosis in A375 human melanoma cells. Colloids Surf. B, 2008, 67, 26-31.

29. Hamouda, T. et al., A novel surfactant nanoemulsion with broadspectrum sporicidal activity against Bacillus species. Infect. Dis., 1999, 180, 1939.

30. Klabunde, K. J. et al., Nanocrystals as stoichiometric reagents with unique surface chemistry. Phys. Chem., 1996, 12, 142.

31. Stoimenov, P. K., Klinger, R. L., Marchin, G. L. and Klabunde, K. J., Metal oxide nanoparticles as bactericidal agents. Langmuir, 2002, 18, 6679 .

32. Zhang, L., Jiang, Y., Ding, Y., Malcolm, P. and David, Y., Investigation into the antibacterial behaviour of suspensions of $\mathrm{ZnO}$ nanoparticles (ZnO nanofluids). J. Nanopart. Res., 2007, 9, 479.

33. Chudobova, D., Cihalova, K., Dostalova, S., Ruttkay-Nedecky, B., Rodrigo, M. A. M. and Tmejova, K., Comparison of the effects of silver phosphate and selenium nanoparticles on Staphylococcus aureus growth reveals potential for selenium particles to prevent infection. FEMS Microbiol. Lett., 2014, 351(2), 195-201.

Received 29 June 2018; revised accepted 22 October 2018

doi: $10.18520 / \mathrm{cs} / \mathrm{v} 116 / \mathrm{i} 2 / 285-290$ 